\title{
NYLON \\ A Factor In \\ STRESS CORROSION \\ Of Aluminum Bronze
}

\author{
by E. J. Silk
}

$S^{\mathrm{T}}$ RESS corrosion cracking of aluminum bronze occasionally has been mentioned in technical literature. Plastics in contact with stressed aluminum bronze in tap water may cause stress corrosion cracking.

Stress corrosion cracking occurred in a clamp ring of aluminum bronze in contact with a nylon part in service in city water. The assembly consisted of a nylon part held to a stainless steel part by means of silicon-bronze screws through the clamp ring. The aluminum bronze clamp ring failed in a brittle mahner at two points diametrically opposite and at right angles to the screw holes. The aluminum bronze was of the following composition: 94.5 pct $\mathrm{Cu} ; 5.2$ pct $\mathrm{Al}$; 0.001 pet $\mathrm{Pb} ; 0.04$ pct $\mathrm{Fe}$; and 0.20 pct As. This alloy had been chosen specifically because of its superior resistance to stress corrosion. The clamp rings tested prior to assembly showed that the material apparently was satisfactory in that it was ductile, and several broke at a reported stress of $105,000 \mathrm{psi}$.

One half of one of the aluminum bronze rings that had failed in service subsequently was tested in tension and shown to be quite ductile. A macroscopic examination indicated that the fracture was of the brittle type. No deformation was detected, whereas the samples that had been pulled in tension showed marked deformation.

On the other hand, the ring that failed in service showed distinct evidence of a stress corrosion failure. The major fracture was intergranular; and a second crack of the same nature was found immediately adjacent to the original fracture, apparently originating on the inside surface and extending approximately $1 / 3$ across the section as shown in Fig. 1 . A third intergranular crack was found approximately $1 / 8$ in. away from the original fracture and also originated at the inside surface of the ring, Fig. 2. Both photomicrographs indicate a uniformly satisfactory structure. Hardness tests gave uniform results; the total range was $R_{15 \mathrm{~N}} 83$ to 88.5 , with an average of $R_{15 \mathrm{~N}} 87$, approximately equivalent to $R_{B} 81$. Evidence indicated that the cracks, and very probably the fracture, originated at the inside surface in contact or in relatively close proximity to the nylon gear. Fig. 3 is an end view of the assembly showing the relationship of the various components. The distortion of the aluminum bronze ring is evident and to be expected. The reported characteristics of all the failures encountered definitely placed the area of failure as being in contact with the nylon gear.

A number of the nylon parts were tested qualitatively for ammonia using the Nessler Reagent. All samples tested indicated the presence of trace amounts of ammonia, but it is questionable whether

E. J. SILK is Senior Metallurgist at Sam Tour \& Co., Inc., New York.

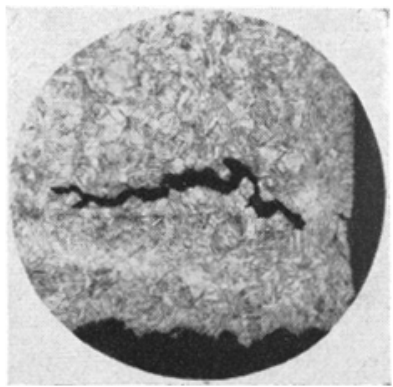

Fig. 1-Original intergranular fracture and second in. tergranular crack adjacent to it. $\mathrm{X} 100$

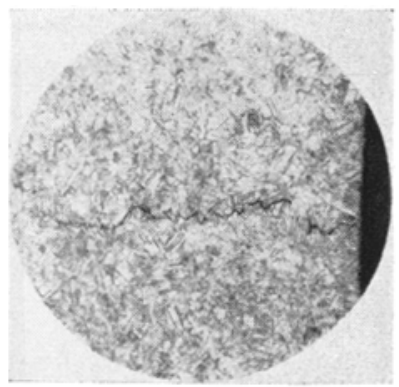

Fig. 2-Third intergranular crack that originated at in side surface of the ring. $\mathrm{X} 100$. nylon in tap water will release ammonia. Nylons are complex polyamides, produced by the polymerization of dibasic acids and diamines. The resultant product is a complex linear polyamide. Amides as chemical compounds are hydrolyzed in the presence of mineral acid or alkali to form the corresponding organic acid and release ammonia. The reaction between nylon polyamide and the strong alkali present in the Nessler Reagent may have produced the ammonia, thereby giving a positive ammonia test. The hydrolysis reaction is more pronounced in acid than alkali solution and at elevated temperatures. As a possible source of amines from nylon, there may have been some residual diamines, which did not polymerize in the manufacture of the nylon.

In view of the definite evidence of a stress corrosion failure, and the fact that the aluminum bronze was metallurgically free of defects, it was only possible to conclude that the nylon gear was the contributing factor to the stress corrosion failure.

Fig. 3. End view of assembly showing the relationship of the various components.

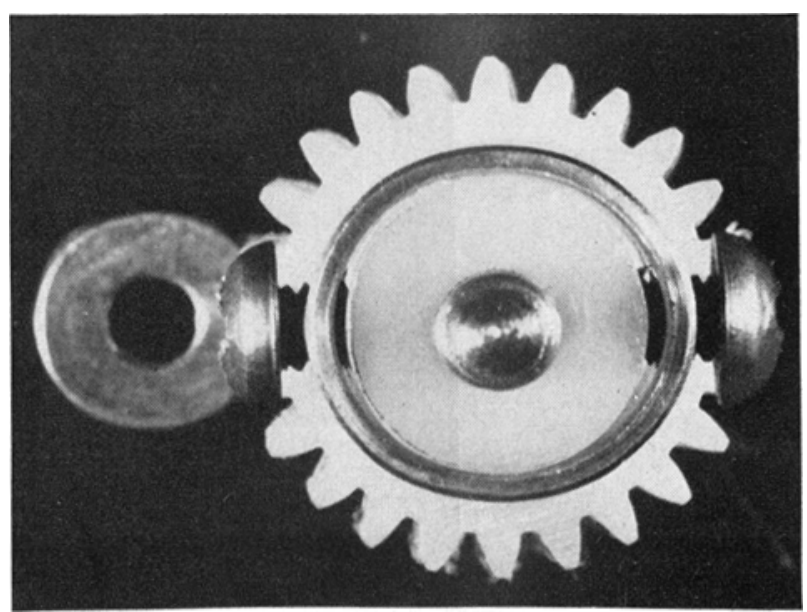

